\title{
Winter is coming; time to ensure the right care, in the right place, for the right length of time
}

So as this edition of Clinical Medicine arrives with you, memories of summer sun and well-earned holidays will becoming more distant and our attention will be increasingly focused on preparing for the next round of winter pressures. There are already stark warnings being expressed that this could be the toughest winter the NHS has faced to date and the unseemly recent spat between Hawking and Hunt does not give the impression that the government is in the mood to compromise or listen.

As winter pressures loom large, we will once again face the challenges of trying to maintain appropriate care and flow of patients through our admission units and wards. Essential to this is ensuring that, particularly in the admissions unit, we undertake the most appropriate and timely investigations and deliver the required therapies but do not get drawn into trying to address chronic complains that may already be being followed up, or be more appropriately dealt with in another way.

Within the pages of this edition are several articles that provide evidence and advice on common acute conditions where simple processes may allow us to safely discharge patients, without being drawn into unnecessary additional clinical concerns. The research paper on diabetic ketoacidosis management ${ }^{1}$ is both simple and elegant and provides a potential framework to minimise length of stay, whereas the issue of cognitive screening in acute admissions is tackled by Phelps et $a l^{2}$ and suggests that, while it can identify those with acute confusion and delirium, it is not a useful process for the determination of new onset dementia. Direct current cardioversion (DCCV) for those with acute atrial fibrillation is discussed in detail by Rankin and Rankin ${ }^{3}$ and they remind us that this common condition is often associated with comorbidities that may increase the risk of thromboembolism. DCCV may not be appropriate for all who have $<48$ hours symptoms and delayed DCCV may be more appropriate in many cases. Finally, the succinct concise guidelines on ulcerative colitis provide a ready summary of current best practice and optimal care. ${ }^{4}$

The excellent CME section focuses on nuclear medicine and provides an update on novel radionuclides, the increasing use of PET MRI ${ }^{5}$ and the expanding role of nuclear medicine in the identification and management of not just malignancies, but thyroid disease, infection and sepsis to name a few. With the usual acute medical cases, lessons and images of the month, there is hopefully something for everyone.

From the last edition, the update on Shape of Training has, unsurprisingly, generated much debate and I am grateful for the letters written to me as editor-in-chief that allow the opinions of members and fellows to be captured and shared, not just on this issue, but any of the content we produce.

As the Royal College of Physicians approaches its 500-year anniversary celebrations, the editorial board are also looking to the future. While maintaining the quality and relevance of the content of Clinical Medicine, there will be some noticeable changes to the look of the journal in 2018, as well as content that reflects on our illustrious history and some of the biggest challenges we face going forwards. As the college enters its 6th century we hope that we can evolve to remain a relevant, valued and impactful resource to all the members and fellows of the RCP and the wider healthcare profession.

So, until December, enjoy this offering and start preparing for the challenging months ahead!

\section{References}

1 Kempegowda P, Coombs B, Nightingale P et al. Regular and frequent feedback of specific clinical criteria delivers a sustained improvement in the management of diabetic ketoacidosis. Clin Med. 2017;17:389-94.

2 Phelps A, Kingston B, Wharton RM, Pendlebury ST. Routine screening in the general hospital: what happens after discharge to those identified as at risk of dementia? Clin Med 2017;17:395-400.

$\begin{array}{llll}\text { Members of the editorial board } & & & \\ \begin{array}{ll}\text { Wing Commander Edward Nicol } \\ \text { Editor-in-chief }\end{array} & \text { Prof Tahseen Chowdhury } & \text { Dr Alexandra Lake } & \text { Dr Mehool Patel } \\ \text { Cono Ariti } & \text { Dr Nick Cork } & \text { Dr Tom Levett } & \text { Dr Gerrard Phillips } \\ \text { Statistical editor } & \text { Dr Albert Edwards } & \text { Dr Nicola Lomax } & \text { Dr Roby Rakhit } \\ & \text { Dr Kate Evans } & \text { Prof Philip MacCarthy } & \text { Dr Jo Rimmer } \\ \text { Dr Michael Almond } & \text { Dr Johanna Feary } & \text { Prof Yash Mahida } & \text { Prof Phil Smith } \\ \text { Mr Paul Belcher } & \text { Dr Maggie Hammersley } & \text { Dr Chris Marguerie } & \text { Dr Angela Star } \\ \text { Dr Rodger Charlton } & \text { Dr Dylan Harris } & \text { Dr Ravik Mascarenhas } & \text { Prof Cameron Swift } \\ \text { Dr Tim Chevassut } & \text { Prof Brian Hurwitz } & \text { Prof Martin McKee } & \text { Dr Rhys Thomas } \\ & \text { Dr Nicola Jones } & \text { Dr Andrew Medford } & \text { Dr Duncan Wilson }\end{array}$


3 Rankin AJ, Rankin SH. Cardioverting acute atrial fibrillation and the risk of thromboembolism: not all patients are created equal. Clin Med 2017;17:419-23.

4 Tun GSZ, Harris A, Lobo AJ. Ulcerative colitis: management in adults, children and young people - concise guidance. Clin Med 2017;17:429-33.
5 Barrington S, Blower P, Cook G. New horizons in multimodality molecular imaging and novel radiotracers. Clin Med 2017;17:44448.

Wing Commander Ed Nicol Editor-in-chief

\section{Royal College of Physicians Museum and Medicinal Garden}

Visit the Royal College of Physicians (RCP) and discover 500 years of medical history in an acclaimed architectural setting.

The RCP is the oldest medical college in England, and since its foundation in 1518 it has built up magnificent collections of books, manuscripts, portraits, silver, and medical artefacts.

Our celebrated Grade I listed headquarters in Regent's Park is the creation of British architect Sir Denys Lasdun and our garden contains over 1,300 plants, each used as medicine around the world over the past 3,000 years.

\section{Guided tours}

We offer guided tours of the building and garden, and welcome bookings for groups of six or more. Refreshments can be booked and tours tailored for special interest groups. Guided tour charges are $£ 5$ per person (refreshments extra).

Royal College of Physicians, 11 St Andrews Place, Regent's Park, London NW1 4LE. Open: Monday- Friday, $9 \mathrm{am}-5 \mathrm{pm}$, free entry

Library, Archive and Museum Services

Tel: +44 (0)203075 1543

Email: history@rcplondon.ac.uk

\section{Free} entry

\section{Royal College} of Physicians

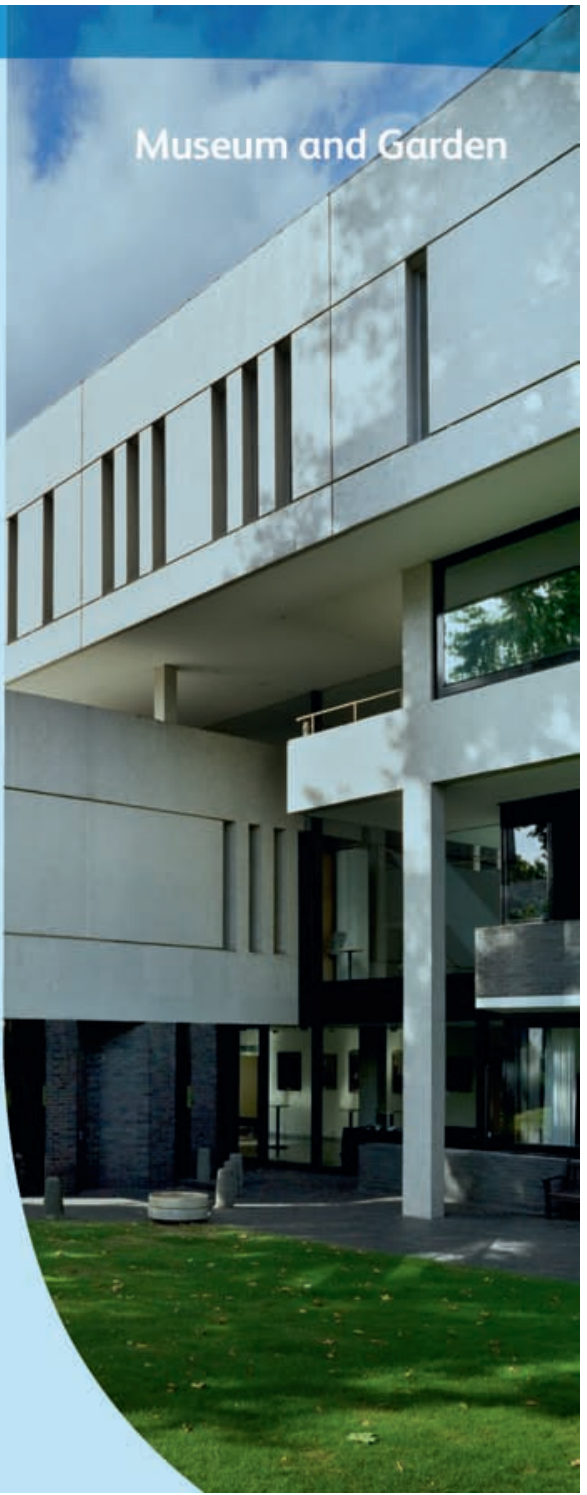

